\title{
Bladder neck placement of a synthetic polypropylene sling for the treatment of stress urinary incontinence
}

\author{
Louise C. McLoughlin; M. Gleeson; S. Francis; C. O’Rourke; H.D. Flood \\ Department of Urology, University Hospital Limerick, Limerick, Ireland
}

Cite as: Can Urol Assoc J 2018 June 8; Epub ahead of print. http://dx.doi.org/10.5489/cuaj.5161

Published online June 8, 2018

\begin{abstract}
Introduction: Pubo-vaginal sling placed at the bladder neck has been the gold standard treatment for stress urinary incontinence (SUI). The synthetic midurethral sling (MUS) is now widely used, as morbidity rates with this technique are substantially reduced. This is an initial report on long-term outcomes of a polypropylene sling (PPS) placed in the traditional bladder neck location.
\end{abstract}

Methods: A retrospective analysis of all patients who underwent PPS insertion at our institution between 2006 and 2014 was conducted. Patient and urodynamic demographics were recorded. Subjective and objective measures of success were determined by postoperative pad usage and validated incontinence questionnaires. Results: A total of 170 patients were followed for a median of four (range 1-8) years. The mean age was $51( \pm 10)$ years. Subjective response was assessed in $57 \%$ of patients; the overall subjective cure rate was $85.3 \%(n=145)$, subjective improvement rate was $4.1 \%(n=7)$, and the subjective failure rate was $10.6 \%(n=18)$. The mean Urogenital Distress Inventory (UDI)-6 score was $6.5( \pm 5.6)$ out of a maximum score of 24 and the Incontinence Impact Questionnaire (IIQ)-7 score was 5.5 ( \pm 6.3 ) out of a maximum score of 28 . There was no significant difference in objective outcome measures in those with an ALPP $</>60 \mathrm{cmH}_{2} \mathrm{O}$.

Conclusion: Bladder neck placement of a PPS resulted in cure rates of $85 \%$ in this series. SUI secondary to intrinsic sphincter deficiency (ISD) and urethral hypermobility were treated with equal success. Bladder neck PPS placement has a role in the treatment of SUI. Our data may well reassure rectus fascia sling (RFS) surgeons who wish to take advantage of faster postoperative recovery using the less invasive PPS placed at the bladder neck. 


\section{Introduction}

SUI is the involuntary leakage of urine on effort or exertion, with a reported prevalence of 12-46\%(1-3). Urodynamic SUI is involuntary leakage observed during filling cystometry; it is associated with increased intra-abdominal pressure in the absence of a detrusor contraction (4). Two mechanisms for SUI are recognized; hyper-mobility of the urethra or bladder neck during exertion, and ISD (5). ALPP is measured on pre-operative urodynamics, which can indicate the presence of ISD. Surgical treatment for SUI aims to improve the support and reduce mobility of the urethro-vesical junction with the use of a suburethral sling; which is now used to treat SUI secondary to urethral hypermobility and ISD.

Giordano (6) initially introduced the concept of suburethral support in 1907 using pedicled gracilis muscle graft as a retropubic sling at the bladder neck. Several procedures for SUI treatment have since been described. In the early 1900's, Stoeckel hypothesized that a proximal urethral position at the bladder neck, and attachment of the sling to the abdominal muscles, were the critical factors for success, rather than the sling material used (7). The Aldridge pedicled RFS was introduced in 1942 (8), further modification was undertaken by McGuire and Lytton in 1978 (9) who placed the RFS proximally at the bladder neck, to achieve continence in $80 \%$ of patients with ISD. In 1991 Blaivas and Jacobs pioneered the placement of loose RFS and found a significant reduction in the incidence of post-operative urinary retention and requirement for self intermittent catheterization (SIC) (10). These sling procedures all involved proximal placement of the sling at the bladder neck. Following this, the clinical indications for use of this type of loose sling were extended to include SUI due to urethral hypermobility as well as $\operatorname{ISD}(11,12)$.

Synthetic polypropylene was then introduced as a sling material (13). This new procedure involved placement of a tension-free vaginal tape (TVT) at the mid urethra rather than the bladder neck with the intention of reinforcing the weakened pubo-urethral ligaments and recreating the "hammock" support of the lax anterior vaginal wall and endopelvic fascia. Results published by Ulmsten et al (14) demonstrated decreased operative time, decreased recovery time and good outcomes due to the less invasive nature of the procedure. The Ulmsten needle was passed from below upward, rather than the reverse, as is usually the case with RFS. Initial concerns by RFS surgeons about excessive risk of erosion and infection secondary to synthetic sling material proved unfounded, with long-term data from experienced surgeons (15-18). From 2006 onward we offered PPS (instead of RFS) as our first choice for the treatment of uncomplicated SUI but continued to use the longestablished McGuire technique of sling placement at the bladder neck. While we recognize that use of the sling in this way is technically off-label, we believe this method is in keeping with the principles of bladder neck support and closure, which have been well described.

Herein, we report outcomes of bladder neck placement of PPS in a single surgeon series. This is the first report of PPS placement at the bladder neck. 


\section{Methods}

A retrospective analysis of all patients who underwent PPS for SUI at our institution between 2006 and 2014 was conducted. We use the SPARC ${ }^{\mathrm{TM}}$ self-fixating sling system (AMS, Endo International PLC, Dublin, Ireland), incorporating an AMS macroporous, monofilament, sheath-protected PPS. Patients were fully consented for bladder neck placement of the sling at time of surgery. Data were collected from the Hospital In-Patient Enquiry system and from urodynamic records. We recorded patient demographics and pre-operative urodynamic data: ALPP and bladder capacity (volume) at ALLP. Methods, definitions, and units used, conform to the standards recommended by the International Continence Society (19). A post-operative telephone survey was conducted to evaluate success rates. Subjective success, improvement and failure were defined as "pad free", "reduced pad usage” and "recurrence of incontinence post operatively with no reduction in pad usage" respectively. Objective measures of success were determined using the Urogenital Distress Inventory (UDI-6) and the Incontinence Impact Questionnaire (IIQ-7); short forms of the original UDI and IIQ. Both are validated questionnaires for assessing symptom distress and quality of life in both men and women $(20,21)$. IBM ${ }^{\circledR}$ SPSS ${ }^{\circledR}$ v23 was used to perform statistical analysis. Categorical data were analysed using Fischer's exact test, continuous data were analysed using T-test.

\section{Procedure description}

Our approach involved the McGuire "bladder neck placement" technique using a PPS $\left(\right.$ SPARC $\left.^{\mathrm{TM}}\right)$ instead of RFS. All procedures were carried out under general anesthesia. Bladder neck position was determined by placing gentle traction on a Foley catheter and palpating the balloon, a small midline incision was made in this area. Dissection to the endopelvic fascia was performed in the usual fashion. The endopelvic fascia was penetrated from below to enter the retropubic space in cases where previous surgery or pelvic injury made it difficult to palpate the needle tip above. Trochars were guided from up-down; the sling was attached to the trochars and pulled into position at the bladder neck. The tape was generally placed without tension. In cases with a degree of ISD, or failed previous sling procedure, a variable degree of tension was applied. A thorough urethro-cystoscopy was performed using a $70^{\circ}$ telescope, ensuring perforation had not occurred. The vaginal wall was closed with interrupted 2/0 Vicryl vertical mattress sutures. A Foley catheter and vaginal pack were left in situ. The pack and catheter were removed on the morning of postoperative day one. If the patient was unable to void by the time of discharge they were taught SIC, to be continued until spontaneous, efficient voiding resumed.

\section{Results}

Demographics (Table 1)

300 patients underwent PPS during the timeframe. 170 (57\%) were contactable for telephone survey post-operatively; results of responders are reported on. 170 patients were followed for a median of 4 years (range 1-8). Pre-operative urodynamic data 
were available for analysis on 98 (58\%) patients. All demonstrated GSI and 9 (9\%) had concomitant detrusor over-activity (DO).

Subjective and objective cure (Table 2)

The overall subjective cure rate was $85.3 \%(n=145)$. There was no significant difference in subjective outcomes in patients with pre-operative ALPP $</>60 \mathrm{cmH}_{2} \mathrm{O}$. The mean UDI-6 score was 6.5 ( \pm 5.6$)$ out of a maximum score of 24 and IIQ-7 score was $5.5( \pm 6.3)$ out of a maximum score of 28 , at latest follow up, indicating good objective outcomes. There was no significant difference in the UDI-6 or IIQ7 scores between those with ALPP $</>60 \mathrm{cmH}_{2} \mathrm{O}$.

\section{Subjective failure}

The overall subjective failure rate was $10.6 \%(n=18)$ (Table 2); post-operative urodynamic data were available on $6 / 18$. 5 of these patients had residual GSI with a mean ALPP of $111 \mathrm{cmH}_{2} \mathrm{O} .2 / 5$ underwent a second PPS. The first patient had an ALPP of $82 \mathrm{cmH}_{2} \mathrm{O}$ and had a poor outcome with objective scores of 19 and 20. The ALPP was $145 \mathrm{cmH}_{2} 0$ in the $2^{\text {nd }}$ patient, with excellent outcome scores of 4 and 0. RFS was performed in 2/5 (ALPP of $140 \mathrm{cmH}_{2} \mathrm{O}$ and $70 \mathrm{cmH}_{2} \mathrm{O}$ respectively). Both had poor outcome scores with UDI- 6 of 20 and 23, and IIQ-7 of 22 and 22 respectively. The $5^{\text {th }}$ patient elected for no further anti-SUI treatment and was instead treated for storage symptoms with anti-muscarinics and intravesical Botox. The $6^{\text {th }}$ patient had no urodynamic abnormality but had additional anti-incontinence procedures including intra-urethral bulking agents and a RFS with good objective outcome scores of 7 and 9.

Post-operative urodynamic data were unavailable in 12/18 with subjective failure. 2 of these patients were treated with a $2^{\text {nd }}$ PPS and intra-urethral bulking agents with mean objective outcome scores of 15 and 14. A combination of RFS and urethral bulking agents was used in 4 of these patients; and 5 were treated with intraurethral bulking agents alone. The $12^{\text {th }}$ patient elected for no further treatment.

Post-operative events (Table 3)

De novo U/UUI was treated with anti-muscarinics in 5 patients, 3 received intravesical Botox, and 3 were treated with combined anti-muscarinics and Botox. The vaginal sling exposure developed after 1.5 years and was managed by local excision of the exposed sling. Bladder perforation was immediately recognised at cystoscopy and managed by removing and repositioning the needle. Urethrolysis was performed in one patient who had a long term (>4week) requirement for self catheterisation.

\section{Discussion}

We report objective and subjective outcomes following bladder neck PPS placement for all types of SUI. We have now replaced RFS with PPS as the surgical treatment of first choice. PPS results in significantly shorter hospital stay, decreased catheterisation time, use of analgesics and loss of days of work when compared to 
RFS (22). Minimal vaginal dissection, the application of a specific PP tape, tensionfree, under the mid-urethra, and no bony fixation of the tape, all result in a technically more straightforward procedure with increased efficacy and safety (16). The "tensionfree” insertion of PPS is standard practice, however certain patient factors, namely ISD or failed previous sling surgery, influenced us to insert the tape under a variable degree of tension. We believe this modification is necessary to obtain good outcomes is these specific clinical scenarios. PPS use was initially recommended as a primary operation for GSI, it is now used in complex cases, such as failure after traditional anti-incontinence surgery (16). Redo surgery with PPS was performed in 4 patients in our series with initial failure of PPS with mixed results.

A Cochrane review of MUS for SUI reported short ( $<1$ year) and long ( $>5$ year) subjective cure rates of $71-97 \%$ and $51-88 \%$ respectively. Subjective cure was assessed by self-reporting of participants and responses to symptom-based questionnaires (15). Deval et al (23) and Ulmsten et al (18) reported subjective cure rates of $70 \%$ and $85 \%$ respectively in large studies on TVT for SUI , and cure rates of $74 \%$ have been reported on mid-urethral TVT for ISD (17). A recent systematic review of surgical treatments of SUI demonstrated similar cure rates in the MUS and RFS group and a trend towards a higher re-operation rate in the MUS group (24). Our subjective cure rate of $85 \%$ with bladder neck placement, after median 4 year follow up, compares favorably with the literature (Table 4).

We therefore offer a PPS as first choice for the treatment of uncomplicated SUI but continued to use the long-established McGuire technique of sling placement at the bladder neck. Bladder neck placement, instead of the now traditional method of mid-urethral placement, is in keeping with the principles of bladder neck support and closure, which have been describe by autologous sling surgeons since the early 1900's. The technique of mid-urethral sling placement was introduced as it lends to the 'hammock' theory of mid-urethral support, but the traditional teaching is that proximal urethral placement is an important factor for success in SUI surgery.

Malposition of MUS at the bladder neck has been associated with adverse outcomes in the literature (25-27). These reports describe an excessive proximal location of the urethral tape relative to the mid-urethra, and resulting in recurrent SUI post operatively. In our series the tape has been deliberately placed at the bladder neck, with results equaling large MUS studies (Table 4). We therefore hypothesize that it is the malposition of the tape relative to its intended location, the mid-urethra, that resulted in failure, rather than the bladder neck location.

\section{De novo UUI rates}

Overactive bladder symptoms such as U and UUI can be associated with SUI; the precise mechanism of which is poorly understood (28). An average de novo U/UUI rate of $8.35 \%$ for synthetic MUS has been reported (15). Persistent UUI rates of 11$67 \%$ and de novo UUI rates of $0-30 \%$ have been reported in RFS studies (29). Our rate of $8.8 \%$ after bladder neck PPS placement is therefore similar or better than that reported for MUS and RFS. 


\section{Voiding dysfunction/ tape erosion rates}

Urethral obstruction requiring surgery or long term SIC has been reported in 1-7\% of patients undergoing RFS (29). We attribute our low urethral obstruction rate of $0.5 \%$ to surgeon technical experience and careful patient selection to identify those with poor detrusor contractility on pre-operative urodynamics. $0.5 \%$ of our patients developed a vaginal sling exposure, comparing favorably with the reported rate of $1.5 \%$ (15). None of our patients developed a urethral/bladder neck erosion and we hypothesize this is due to its bladder neck location, where is additional tissue support when compared to the mid-urethra.

\section{Bladder perforation}

The bladder perforation rate after synthetic MUS insertion is $2.5 \%$ (15), comparable to our rate of $2.9 \%$. This is lower than generally reported for top-down needle placement such as the SPARC procedure (10.5\%) (30) and is likely attributable to surgeon experience and technique. A post-operative pelvic haematoma was seen in $1.2 \%$ of our patients. This is in keeping with the reported rate of $0.7 \%-1.9 \%$ (15).

SUI can be classified on the basis of urethral hypermobility and/or ISD, determined by measuring the ALPP level, and by direct or flurourodynamic observation of urethral motion. There is no strict definition, but it is thought to occur in those with a urethral resting pressure of $\leq 20 \mathrm{cmH}_{2} \mathrm{O}(16)$. McGuire's methodology to evaluate urethral sphincteric function was to measure the abdominal or valsalva LPP on urodynamics (31). An ALPP of $<60 \mathrm{cmH}_{2} 0$ indicating ISD while an ALPP $>$ $90 \mathrm{CmH}_{2} \mathrm{O}$ indicating urethral hypermobility primarily (11). Both entities have been successfully treated with PPS. However, the incidence of sling failure is greatest in those $>70$ years, with a low urethral resting pressure $\left(\leq 10 \mathrm{cmH}_{2} 0\right)$ and in whom the urethra is immobile (16). As expected, the ALPP was $>60 \mathrm{cmH}_{2} \mathrm{O}$ in significantly more patients in our cohort. Interestingly, the subjective outcomes were not significantly different in terms of subjective or objective cure rates, improvement and failure rates in those with ALPP $>$ and $<60 \mathrm{~cm} \mathrm{H}_{2} \mathrm{O}$.

We accept there are a number of limitations with out study. Due to the retrospective nature of the study design, baseline symptom assessment for comparison with post-operative results is lacking. Our telephone survey received a response rate of $57 \%$, and therefore we have not captured outcome data on $43 \%$. There is a possibility of bias in that those with poor outcomes may be unwilling to participate in the study and we therefore may not be able to extrapolate the subjective and objective outcome results to the $43 \%$ of the cohort who remain unsurveyed. We remain confident that we have captured all our complications as our institutional referral pattern is such that patients with post-operative complications are unlikely to be referred elsewhere. Our data on short term ( $<4$ weeks) SIC was incomplete and therefore not reported. The strengths of the study are its homogeneity as singlesurgeon, single-center study, increasing the validity of the results, and a median follow up period of 4 years, ranging up to 8 years. 
We suggest that our low incidence of vaginal tape exposure and high subjective cure rates are related to accurate placement of the tape at the bladder neck level (as in the classic RFS) where the tape is at a slightly deeper level than at the mid-urethra. We also believe that an interrupted mattress closure of the vagina protects against subsequent exposure.

\section{Conclusion}

Bladder neck placement of a PPS is at least as efficacious as mid-urethral placement, in our surveryed cohort. We report a lower incidence of vaginal tape exposure than quoted in the literature. In addition, there is significantly reduced postoperative morbidity in comparison to the RFS. We report a very low incidence of persistent (>4weeks) voiding dysfunction post-operatively. We had no cases of urethral or bladder exposure/erosion in our series. Using both subjective and objective measures of success, our approach is effective for both the treatment of SUI secondary to ISD and urethral hypermobility. Bladder neck PPS placement may have an important role in the surgical treatment of SUI. 


\section{References}

1. Irwin DE, Milsom I, Hunskaar S, Reilly K, Kopp Z, Herschorn S, et al. Population-based survey of urinary incontinence, overactive bladder, and other lower urinary tract symptoms in five countries: results of the EPIC study. Eur Urol. 2006;50(6):1306-14; discussion 14-5.

2. Botlero R, Urquhart DM, Davis SR, Bell RJ. Prevalence and incidence of urinary incontinence in women: review of the literature and investigation of methodological issues. Int J Urol. 2008;15(3):230-4.

3. Van Kerrebroeck PE, Kelleher CJ, Coyne KS, Kopp Z, Brodsky M, Wang JT. Correlations among improvements in urgency urinary incontinence, healthrelated quality of life, and perception of bladder-related problems in incontinent subjects with overactive bladder treated with tolterodine or placebo. Health Qual Life Outcomes. 2009;7:13.

4. Haylen BT, de Ridder D, Freeman RM, Swift SE, Berghmans B, Lee J, et al. An International Urogynecological Association (IUGA)/International Continence Society (ICS) joint report on the terminology for female pelvic floor dysfunction. Neurourol Urodyn. 2010;29(1):4-20.

5. Blaivas JG, Olsson CA. Stress incontinence: classification and surgical approach. J Urol. 1988;139(4):727-31.

6. Giordano D. Twentieth Congress. Franc de Chir. 1907;506.

7. Stoeckel W. Über die Verwendung der Musc. pyramidales bei der operativen Behandlung der lncontinentia urinae (About the use of the muculi pyramidales for the surgical treatment of incontinentia urinae). Allgemeine Gynakologie und Urologie. 1917;41(11).

8. A.H. A. Transplantation of fascia for the relief of urinary incontinence. Am J Obstet Gynecol. 1942;44:398-411.

9. McGuire EJ, Lytton B. Pubovaginal sling procedure for stress incontinence. J Urol. 1978;119(1):82-4.

10. Blaivas JG, Jacobs BZ. Pubovaginal fascial sling for the treatment of complicated stress urinary incontinence. J Urol. 1991;145(6):1214-8.

11. Cross CA, Cespedes RD, McGuire EJ. Our experience with pubovaginal slings in patients with stress urinary incontinence. J Urol. 1998;159(4):1195-8.

12. Chaikin DC, Blaivas JG, Rosenthal JE, Weiss JP. Results of pubovaginal sling for stress incontinence: a prospective comparison of 4 instruments for outcome analysis. J Urol. 1999;162(5):1670-3.

13. J.E. M. A sling operation using Marlex polypropelene mesh, for treatment of recurrent stress incontinence. Am J Obstst Gynecol. 1970;106:369-77.

14. Ulmsten U, Henriksson L, Johnson P, Varhos G. An ambulatory surgical procedure under local anesthesia for treatment of female urinary incontinence. International urogynecology journal and pelvic floor dysfunction. 1996;7(2):81-5; discussion 5-6. 
15. Ford AA, Rogerson L, Cody JD, Ogah J. Mid-urethral sling operations for stress urinary incontinence in women. The Cochrane database of systematic reviews. 2015(7):CD006375.

16. Ulmsten U. An introduction to tension-free vaginal tape (TVT)--a new surgical procedure for treatment of female urinary incontinence. International urogynecology journal and pelvic floor dysfunction. 2001;12 Suppl 2:S3-4.

17. Rezapour M, Ulmsten U. Tension-Free vaginal tape (TVT) in women with recurrent stress urinary incontinence--a long-term follow up. International urogynecology journal and pelvic floor dysfunction. 2001;12 Suppl 2:S9-11.

18. Nilsson CG, Kuuva N, Falconer C, Rezapour M, Ulmsten U. Long-term results of the tension-free vaginal tape (TVT) procedure for surgical treatment of female stress urinary incontinence. International urogynecology journal and pelvic floor dysfunction. 2001;12 Suppl 2:S5-8.

19. Abrams P, Cardozo L, Fall M, Griffiths D, Rosier P, Ulmsten U, et al. The standardisation of terminology of lower urinary tract function: report from the Standardisation Sub-committee of the International Continence Society. Neurourology and urodynamics. 2002;21(2):167-78.

20. Utomo E, Korfage IJ, Wildhagen MF, Steensma AB, Bangma CH, Blok BF. Validation of the Urogenital Distress Inventory (UDI-6) and Incontinence Impact Questionnaire (IIQ-7) in a Dutch population. Neurourol Urodyn. 2015;34(1):24-31.

21. Uebersax JS, Wyman JF, Shumaker SA, McClish DK, Fantl JA. Short forms to assess life quality and symptom distress for urinary incontinence in women: the Incontinence Impact Questionnaire and the Urogenital Distress Inventory. Continence Program for Women Research Group. Neurourology and urodynamics. 1995;14(2):131-9.

22. Kaplan SA, Santarosa RP, Te AE. Comparison of fascial and vaginal wall slings in the management of intrinsic sphincter deficiency. Urology. 1996;47(6):885-9.

23. Deval B, Jeffry L, Al Najjar F, Soriano D, Darai E. Determinants of patient dissatisfaction after a tension-free vaginal tape procedure for urinary incontinence. J Urol. 2002;167(5):2093-7.

24. Fusco F, Abdel-Fattah M, Chapple CR, Creta M, La Falce S, Waltregny D, et al. Updated Systematic Review and Meta-analysis of the Comparative Data on Colposuspensions, Pubovaginal Slings, and Midurethral Tapes in the Surgical Treatment of Female Stress Urinary Incontinence. European urology. 2017;72(4):567-91.

25. Poon C, Zimmern P. When the sling is too proximal: A specific mechanism of persistent stress incontinence after pubovaginal sling placement. Urology. 2004;64(2):287-91.

26. Kociszewski J, Rautenberg O, Perucchini D, Eberhard J, Geissbuhler V, Hilgers R, et al. Tape functionality: sonographic tape characteristics and 
outcome after TVT incontinence surgery. Neurourology and urodynamics. 2008;27(6):485-90.

27. Gilchrist AS, Rovner ES. Sling Location in Women With Recurrent Stress Urinary Incontinence Following Midurethral Sling. Urology. 2012;79(1):76-9.

28. Mitsui T, Tanaka H, Moriya K, Kakizaki H, Nonomura K. Clinical and urodynamic outcomes of pubovaginal sling procedure with autologous rectus fascia for stress urinary incontinence. International journal of urology : official journal of the Japanese Urological Association. 2007;14(12):1076-9.

29. Blaivas JG, Chaikin DC. Pubovaginal fascial sling for the treatment of all types of stress urinary incontinence: surgical technique and long-term outcome. The Urologic clinics of North America. 2011;38(1):7-15, v.

30. Deval B, Levardon M, Samain E, Rafii A, Cortesse A, Amarenco G, et al. A French multicenter clinical trial of SPARC for stress urinary incontinence. European urology. 2003;44(2):254-8; discussion 8-9.

31. McGuire EJ, Fitzpatrick CC, Wan J, Bloom D, Sanvordenker J, Ritchey M, et al. Clinical assessment of urethral sphincter function. J Urol. 1993;150(5 Pt 1):1452-4. 
Figures and Tables

\begin{tabular}{|l|l|l|}
\hline \multicolumn{3}{|l|}{ Table 1. Patient demographics } \\
\hline \multirow{2}{*}{ Age } & Mean & 51 \\
\cline { 2 - 3 } & SD & 10 \\
\hline \multirow{2}{*}{ BMI $\left(\mathrm{kg} / \mathrm{m}^{2}\right)$} & Mean & 26.7 \\
\cline { 2 - 3 } & SD & 5.7 \\
\hline \multirow{2}{*}{ ALPP $\left(\mathrm{cmH}_{2} \mathrm{O}\right)$} & Mean & 107 \\
\cline { 2 - 3 } & Range & $40-200$ \\
\hline $\begin{array}{l}\text { Bladder volume at } \\
\text { ALPP (mls) }\end{array}$ & Mean & 277 \\
\cline { 2 - 3 } & Range & $99-470$ \\
\hline
\end{tabular}

ALPP: abdominal leak point pressure; SD: standard deviation.

\begin{tabular}{|c|c|c|c|}
\hline \multirow{2}{*}{$\begin{array}{l}\text { Patients } \\
n=98(\%)\end{array}$} & ALPP $<60 \mathrm{mmH}_{2} \mathrm{O}$ & ALPP $>60 \mathrm{mmH}_{2} \mathrm{O}$ & $\mathbf{p}$ \\
\hline & $15(15 \%)$ & $83(85 \%)$ & $<0.0001$ \\
\hline \multicolumn{4}{|c|}{ Subjective outcomes } \\
\hline $\begin{array}{l}\text { Cured } \\
n=85(\%)\end{array}$ & $14(93 \%)$ & $71(86 \%)$ & 0.6846 \\
\hline $\begin{array}{l}\text { Improved } \\
n=6(\%)\end{array}$ & $0(0 \%)$ & $6(7 \%)$ & 0.5863 \\
\hline $\begin{array}{l}\text { Failed } \\
n=7(\%)\end{array}$ & $1(7 \%)$ & $6(7 \%)$ & 1.0 \\
\hline \multicolumn{4}{|c|}{ Objective outcomes } \\
\hline UDI-6 & 7 & 7.2 & 0.9007 \\
\hline IIQ-7 & 5 & 7.2 & 0.2468 \\
\hline
\end{tabular}

ALPP: abdominal leak point pressure; IIQ: incontinence impact questionnaire; UDI: urogenital distress inventory. 


\begin{tabular}{|l|c|}
\hline \multicolumn{2}{|l|}{ Table 3. Postoperative events } \\
\hline $\begin{array}{l}\text { De novo U/UUI } \\
\text { n (\%) }\end{array}$ & $15(8.8)$ \\
\hline $\begin{array}{l}\text { Urosepsis } \\
\text { n (\%) }\end{array}$ & $1(0.5)$ \\
\hline $\begin{array}{l}\text { Pelvic hematoma } \\
\text { n (\%) }\end{array}$ & $2(1.2)$ \\
\hline $\begin{array}{l}\text { Vaginal sling exposure } \\
\text { n (\%) }\end{array}$ & $1(0.5)$ \\
\hline $\begin{array}{l}\text { Persistent (>4weeks) voiding } \\
\text { obstruction } \\
\text { n (\%) }\end{array}$ & $1(0.5)$ \\
\hline
\end{tabular}

U: urgency; UUI: urge urinary incontinence.

NR: not reported; TVT: trans-vaginal tape; U: urgency; UUI: urge urinary incontinence.

\begin{tabular}{|l|c|c|c|c|c|c|c|}
\hline Table 4. Comparison of outcomes between large TVT studies \\
\hline & $\begin{array}{c}\text { N } \\
\text { (patients) }\end{array}$ & $\begin{array}{c}\text { Mean } \\
\text { Followup } \\
\text { (month) }\end{array}$ & $\begin{array}{c}\text { Subjective } \\
\text { cure rate }\end{array}$ & $\begin{array}{c}\text { De } \\
\text { novo } \\
\text { U/UUI }\end{array}$ & $\begin{array}{c}\text { Vaginal } \\
\text { tape } \\
\text { exposure }\end{array}$ & $\begin{array}{c}\text { Bladder } \\
\text { perforation }\end{array}$ & $\begin{array}{c}\text { Retropubic } \\
\text { hematoma }\end{array}$ \\
\hline $\begin{array}{l}\text { McLoughlin } \\
\text { et al (2017) }\end{array}$ & 170 & 48 & $85 \%$ & $8.8 \%$ & $0.5 \%$ & $2.9 \%$ & $1.2 \%$ \\
\hline $\begin{array}{l}\text { Cochrane } \\
\text { review of } \\
\text { mid-urethral } \\
\text { slings } \\
\text { (2015) }\end{array}$ & n/a & n/a & $51-88 \%$ & $8.35 \%$ & $1.5 \%$ & $2.54 \%$ & $0.7-1.9 \%$ \\
\hline $\begin{array}{l}\text { Deval et al } \\
\text { (2002) }\end{array}$ & 187 & 27 & $70.6 \%$ & $21.3 \%$ & NR & $9.6 \%$ & NR \\
\hline $\begin{array}{l}\text { Ulmsten et } \\
\text { al (2001) }\end{array}$ & 90 & 56 & $84.7 \%$ & $5.9 \%$ & $0 \%$ & $1.1 \%$ & $3.3 \%$ \\
\hline
\end{tabular}

